\title{
Intranasal insulin to improve developmental delay in children with 22q13 deletion syndrome: an exploratory clinical trial
}

\author{
H Schmidt, ${ }^{1}$ W Kern, ${ }^{2}$ R Giese, ${ }^{3}$ M Hallschmid, ${ }^{4}$ A Enders ${ }^{3}$
}

${ }^{1}$ Department of Paediatric Endocrinology and Medical Genetics, Dr. von Hauner Children's Hospital, University of Munich, Lindwurmstr. 4, 80337 Munich/Germany; ${ }^{2}$ Departments of Internal Medicine I, University of Lübeck, Ratzeburger Alle 160, Lübeck/Germany: ${ }^{3}$ Department of Paediatric Neurology, Dr. von Hauner Children's Hospital, University of Munich, Lindwurmstr. 4, 80337 Munich, Germany: ${ }^{4}$ Departments of Neuroendocrinology, University of Lübeck, Ratzeburger Alle 160, Lübeck/Germany

Correspondence to: Professor H Schmidt, Dr von Hauner Children's Hospital University of Munich, Lindwurmstr. 4, 80337 Munich, Germany; heinrich.schmidt@ med.uni-muenchen.de

Received 31 July 2008 Revised 29 September 2008 Accepted 2 October 2008

Published Online First

20 October 2008

\begin{abstract}
Background: The 22q13 deletion syndrome (PhelanMcDermid syndrome) is characterised by a global developmental delay, absent or delayed speech, generalised hypotonia, autistic behaviour and characteristic phenotypic features. Intranasal insulin has been shown to improve declarative memory in healthy adult subjects and in patients with Alzheimer disease.
\end{abstract}

Aims: To assess if intranasal insulin is also able to improve the developmental delay in children with 22q13 deletion syndrome.

Methods: We performed exploratory clinical trials in six children with 22q13 deletion syndrome who received intranasal insulin over a period of 1 year. Short-term (during the first 6 weeks) and long-term effects (after 12 months of treatment) on motor skills, cognitive functions, or autonomous functions, speech and communication, emotional state, social behaviour, behavioural disorders, independence in daily living and education were assessed.

Results: The children showed marked short-term improvements in gross and fine motor activities, cognitive functions and educational level. Positive long-term effects were found for fine and gross motor activities, nonverbal communication, cognitive functions and autonomy. Possible side effects were found in one patient who displayed changes in balance, extreme sensitivity to touch and general loss of interest. One patient complained of intermittent nose bleeding.

Conclusions: We conclude that long-term administration of intranasal insulin may benefit motor development, cognitive functions and spontaneous activity in children with 22q13 deletion syndrome.

Besides its involvement in glucose metabolism, insulin also acts as a neuropeptide in the central nervous system, modulating plastic neuronal mechanisms assumed to be involved in memory processing. When given intranasally, insulin reaches the cerebrospinal fluid and alters brain functions without relevant absorption into the bloodstream. ${ }^{6}$ Intranasal insulin administration improves declarative memory in healthy subjects and patients with Alzheimer disease (AD). ${ }^{7-12}$ Assuming that intranasal insulin may be able to at least partially compensate for the cognitive deficits caused by ProSAP/Shank3 haploinsufficiency, we performed exploratory clinical trials in six children with 22q13 deletion syndrome.

The 22q13 deletion syndrome (PhelanMcDermid syndrome), first described by Watt et al in $1985,{ }^{1}$ is characterised by a global developmental delay, generalised hypotonia, inability to reach various physical and mental milestones, severe expressive speech delay or even loss of verbal skills, normal or accelerated growth, and minor physical features..$^{2-4}$ Of particular interest in this microdeletion syndrome is the general developmental impairment, in particular of cognition and memory functions. It is assumed that these features result from haploinsufficiency of the ProSAP2/Shank3 gene, which triggers the production of postsynaptic scaffolding proteins. Consequently, the development of dendritic spines is impaired.

\section{METHODS}

Six children with 22q13 deletion syndrome were enrolled in the study. Written informed consent was obtained from each individual family. All six patients underwent regular examinations by the same examiner. Anthropometric data (height, weight, head circumference) were collected and blood levels of glucose, cortisol and insulin antibodies were determined after 6 and 12 months of treatment.

The six children received intranasal insulin treatment for 12 months. For intranasal administration, insulin (40 IU/ml; Actrapid, Novo Nordisk, Mainz, Germany) was diluted with $0.9 \%$ saline solution to a concentration of $20 \mathrm{IU} / \mathrm{ml}$ so that each $0.1 \mathrm{ml}$ puff from the nasal atomiser (Aero Pump, Hochheim, Germany) contained a dose of 2 IU insulin. Subjects received one dose of 2 IU insulin per day during the first 3 days according to the standard subcutaneous insulin therapy in children with type 1 diabetes mellitus. Dosage was increased gradually at 3 day intervals, until the final dosage of about $0.5-1.5 \mathrm{IU} / \mathrm{kg} / \mathrm{day}$ (TID) was reached. Blood glucose was measured with a portable glucometer 30 minutes after each administration during the initial treatment period-that is, until the maximum treatment dosage was reached. Baseline fasting blood glucose levels in all patients were between 4.2 and $5.0 \mathrm{mmol} / \mathrm{l}$.

Neurodevelopmental examinations were performed before and about 1 year after treatment started. Electroencephalography was performed before the start of treatment. Parents were asked to observe and record (on videotape) new skills, changes in autonomous functions, movement, cognitive abilities, speech development and communication skills, emotional state, social contact, behaviour and independence in daily living. After 6 weeks and 1 year of treatment, the parents were asked to fill in a questionnaire assessing short-term 
(first 6 weeks) and long-term (12 months) treatment effects on a scale ranging from -10 (most extreme degree of aggravation) to +10 (extremely positive development), with 0 indicating no changes. ${ }^{13}$ The German version ${ }^{14}$ has been extended to include additional specific items and a more detailed rating scale. It is an established tool used in the daily routine to assess developmental changes in mentally disabled children, and contains nine sections of questions about developmental status (table 1). Ratings were compared with clinical observations made by the examiner and with observations of psychologists, physiotherapists and occupational therapists made during routine examinations.

\section{RESULTS}

\section{Patient 1}

This was a boy with karyotype 46,XY, r(22).ish $\mathrm{r}(22)$ (p13q13.1)(TUPLE1+, bcr+, ARSA-,Tel22q-). At time of diagnosis, he was 2 years old. The child had marked cognitive developmental delay, absence of expressive speech, autistic behaviour, minor but generalised muscular hypotonia with uncoordinated ataxic movements (walking at 15 months), restlessness, marked sleep disturbance, persistent screaming, mouthing and chewing, normal growth, large fleshy hands and feet, deep-set eyes, pointed chin, dolicocephaly, and dysplastic fingernails and toenails.

At the start of treatment, at the age of 3 years, weight was $13.7 \mathrm{~kg}$ (10th to $25 \mathrm{th}$ centile), $96.5 \mathrm{~cm}$ ( 25 th to 50 th centile). MRI showed an arachnoidal cyst and large cysterna magna. He was on levomepromazin, phenobarbital and pipamperon, and receiving physiotherapy and occupational therapy.

After a few weeks of treatment (maximum dose of intranasal insulin: $20 \mathrm{IU} /$ day), obvious changes were found in sweating, sleeping without interruption, emotional balance, motor functions (eg, moving with improved postural control, steering a tricycle, drawing a line with a pencil), concentration over longer time periods (eg, looking at books, remembering animals after visiting the zoo). The child understood more words, showed empathy and could help when getting dressed, and also ceased his stereotypic behaviour. After 12 months of treatment, the improvement continued, especially in sleep rhythm, motor skills, attention span and expression of emotions. No progress in speech development was recorded (table 2). There were no reported side effects.

\section{Patient 2}

This was a girl with karyotype 46,XX, del(22)(q13).ish $\operatorname{del}(22)$ (q13.3q13.3)(ARSA-). She was 9 months old at the time of diagnosis. At the age of 10 days a large ovarian cyst had been removed. She grew too rapidly during the first 2 years of life and had recurrent upper airway infections. At the age of 16 months, she exhibited global developmental delay. Phenotypic features were a flat middle face, high forehead, deep-set eyes, ptosis, a bulbous nose, and dysplastic nails and finger pads (figs 1, 2).

At the start of treatment, aged 16 months, weight was $12 \mathrm{~kg}$ (97th centile) and height $86 \mathrm{~cm}$ ( $>97$ th centile). MRI showed a narrowed corpus callosum. She was on no medication and was receiving physiotherapy.

The short-term effects of insulin (maximum dose $17.5 \mathrm{IU} /$ day) were normalisation of obstipation and body temperature, greater agility, progress in gross and fine motor functions (eg, reaching across the midline of the body, coordination of complex movements), more perseverance in activities, longer concentration spans. However, as a consequence of increased mobility, more risk-taking behaviour was also noticed. Long-term effects were found for autonomous functions (eg, stable body temperature, fewer infections, uncomplicated eating behaviour, chewing), gross and fine motor functions (eg, more body tension, grasping with more precision), or cognitive performance (eg, longer attention spans). There was progress in nonverbal communication (eg, pointing with her finger) and emotional regulation, and the girl rarely showed stereotypic behaviour. She actively took part in dressing and undressing and could anticipate dangerous situations quite well (table 2). There were no reported side effects.

\section{Patient 3}

This was a girl with karyotype 46, XX, del(22)(q13.33). She was 3 years old at the time of diagnosis. Although she showed

Table 1 Behavioural questionnaire for the assessment of developmental progress ${ }^{13}$

\begin{tabular}{|c|c|}
\hline Section & Categories and items \\
\hline \multirow[t]{3}{*}{ 1. Autonomous functions } & 1. Sweating/body temperature/digestion/defecation (eg, sweats more, sweats less, body temperature better regulated) \\
\hline & 2. Sleeping behaviour (eg, sleeps peacefully, sleeps less/more, can stay awake longer during daytime) \\
\hline & 3. Eating behaviour (eg, shows more appetite, eats more, can be fed longer, with less problems, can feed themselves) \\
\hline \multirow[t]{3}{*}{ 2. Motor skills } & 4. Activity level (eg, moves more/less than before) \\
\hline & 5. Hand movements (eg, grips, manipulates, points better than before ) \\
\hline & 6. Gross motor functions (eg, has made progress, more strength, is more stable) \\
\hline \multirow[t]{3}{*}{ 3. Cognitive abilities } & 7. Attention span (eg, when listening, looking at books, playing) \\
\hline & 8. Interest and motivation in new situations and activities (eg, explores more) \\
\hline & 9. Memory functions (eg, seems to remember sequences better, understands and remembers rules of playing) \\
\hline \multirow[t]{3}{*}{ 4. Speech and Communication } & 10. Understanding speech (eg, understands speech better, is more attentive in listening) \\
\hline & 11. Speech and vocalisation (eg, uses new sounds, new syllables, new words) \\
\hline & 12. Use of nonverbal/alternative ways of communication (eg, looks longer at someone, points, uses gestures in order to express needs) \\
\hline \multirow[t]{3}{*}{ 5. Emotional state } & 13. Emotional stability (eg, agitation, self injury, crying, screaming, shouting, calms down quicker) \\
\hline & 14. Child expresses feelings like, eg, joy, sadness, anger, interest \\
\hline & 15. Child reacts to someone else's feelings, cries or laughs with others \\
\hline 6. Social behaviour & 16. Child shows interest in other children, imitates what others do, feeds the doll \\
\hline 7. Behaviour disorders & $\begin{array}{l}\text { 17. Stereotype movements (eg, repetitive movements with hands or feet, reaction to stress), preferences in playing behaviour (eg, needs } \\
\text { special smells or surfaces) }\end{array}$ \\
\hline 8. Independence in daily living & 18. Changes in daily activities (eg, feeding, dressing, choosing, deciding, using the toilet) \\
\hline \multirow[t]{2}{*}{ 9. Education } & $\begin{array}{l}\text { 19. Education in activities of daily living, eg, child shows more obedient behaviour, accepts compromises more easily, tolerates changes } \\
\text { better }\end{array}$ \\
\hline & 20. Child anticipates dangers/needs control \\
\hline
\end{tabular}


Table 2 Effects of intranasal insulin administration as assessed with a questionnaire on developmental progress after 6 weeks (time t1) and 12 months (time t2) ${ }^{13}$

\begin{tabular}{|c|c|c|c|c|c|c|c|c|c|c|c|c|}
\hline \multirow{2}{*}{$\begin{array}{l}\text { Patient } \\
\text { Sex }\end{array}$} & \multicolumn{2}{|l|}{1} & \multicolumn{2}{|l|}{2} & \multicolumn{2}{|l|}{3} & \multicolumn{2}{|l|}{4} & \multicolumn{2}{|l|}{5} & \multicolumn{2}{|l|}{6} \\
\hline & \multicolumn{2}{|c|}{ Male } & \multicolumn{2}{|c|}{ Female } & \multicolumn{2}{|c|}{ Female } & \multicolumn{2}{|c|}{ Female } & \multicolumn{2}{|c|}{ Male } & \multicolumn{2}{|c|}{ Female } \\
\hline Age* & \multicolumn{2}{|c|}{3 years } & \multicolumn{2}{|c|}{16 months } & \multicolumn{2}{|c|}{8.5 years } & \multicolumn{2}{|c|}{9.5 years } & \multicolumn{2}{|c|}{5.5 years } & \multicolumn{2}{|c|}{26 months } \\
\hline Questions & t1 & t2 & t1 & t2 & t1 & t2 & t1 & t2 & t1 & t2 & t1 & t2 \\
\hline 1 & 5 & 5 & 3 & 7 & 0 & 0 & 0 & 0 & 0 & 0 & 0 & - \\
\hline 2 & 7 & 7 & 0 & 0 & 0 & -1 & 0 & 0 & 0 & 0 & 0 & - \\
\hline 3 & 5 & 5 & 2 & 5 & 0 & 2 & 0 & 2 & 0 & 0 & 5 & - \\
\hline 4 & 7 & 7 & 7 & 8 & -7 & 0 & 2 & 2 & 3 & -2 & 0 & - \\
\hline 5 & 5 & 5 & 6 & 4 & 0 & 3 & 2 & 5 & 0 & 1 & 3 & - \\
\hline 6 & 5 & 5 & 5 & 8 & -3 & 5 & 2 & 4 & 0 & 8 & 2 & - \\
\hline 7 & 8 & 3 & 3 & 3 & 0 & 3 & 3 & 8 & 0 & 3 & 4 & - \\
\hline 8 & 8 & 5 & 2 & 7 & -8 & 0 & 0 & 3 & 3 & 5 & 3 & - \\
\hline 9 & 5 & 3 & 0 & 4 & 0 & 0 & 0 & 4 & 0 & 1 & 3 & - \\
\hline 10 & 8 & 5 & $0-1$ & 7 & 0 & 2 & 2 & 5 & 0 & 3 & 2 & - \\
\hline 11 & 3 & 3 & 0 & 0 & 0 & 5 & 2 & 9 & 0 & 0 & 0 & - \\
\hline 12 & 5 & 3 & 0 & 7 & -5 & 4 & 3 & 8 & 0 & 2 & 3 & - \\
\hline 13 & 6 & 3 & 0 & 0 & -5 & 2 & 2 & 5 & 0 & 1 & 5 & - \\
\hline 14 & 5 & 3 & 0 & 6 & -3 & 2 & 0 & 7 & 0 & 1 & 0 & - \\
\hline 15 & 5 & 5 & 2 & 3 & 0 & 0 & 1 & 4 & 0 & 0 & 0 & - \\
\hline 16 & 5 & 3 & 0 & 8 & -9 & 2 & 1 & 2 & 0 & 2 & 3 & - \\
\hline 17 & 5 & 5 & 2 & 7 & 0 & 0 & 0 & 3 & 0 & -2 & 1 & - \\
\hline 18 & 5 & 5 & 1 & 9 & 0 & 2 & 0 & 6 & 0 & 1 & 0 & - \\
\hline 19 & 5 & 4 & 0 & 4 & 0 & 0 & 2 & 8 & 0 & 0 & 2 & - \\
\hline 20 & 5 & 5 & -7 & 8 & 0 & 0 & 0 & 2 & 0 & 1 & 0 & - \\
\hline
\end{tabular}

${ }^{*}$ At time treatment onset is indicated.

Note that treatment was stopped after 5 weeks in patient 3 but subsequent long-term effects were assessed; no long-term data are available for patient 6 .

hypotonia during the first 2 years, she could sit and walk without assistance quite early, and was skiing and swimming at the age of 8.5 years. Vocalisation started at the age of 2 years, but she spoke only two-word sentences. She was restless, with a short attention span, and showed aggressive and autistic behaviour. She had deep-set eyes and dysplastic flat finger

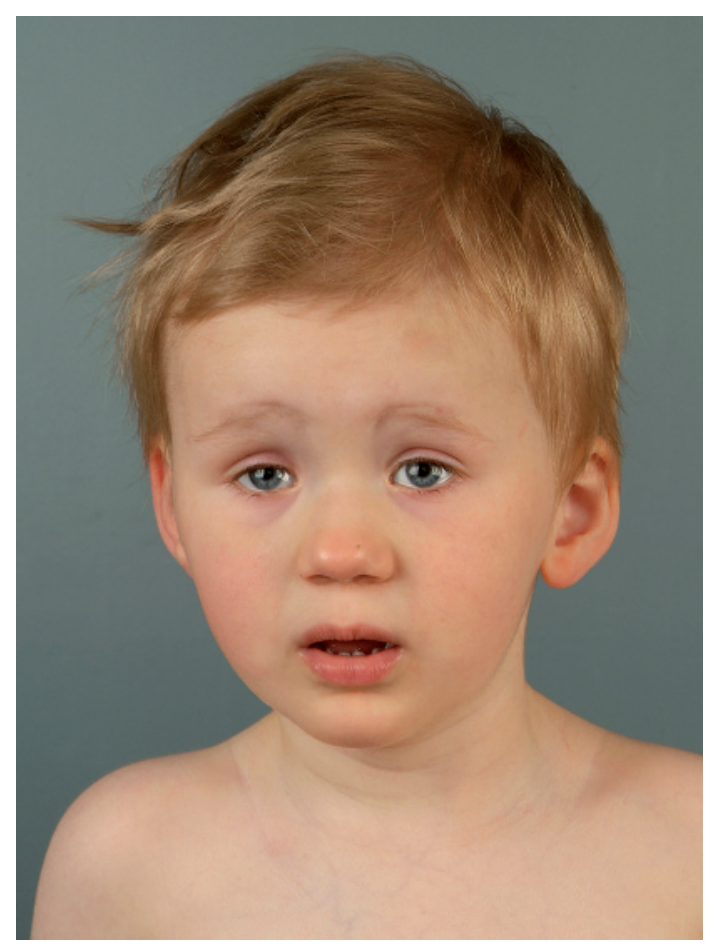

Figure 1 Patient 2. Characteristic facial phenotype. nails. She was receiving physical, speech and occupational therapy.

At the start of treatment, she was aged 8.5 years, with weight of $28 \mathrm{~kg}$ (50-75th centile), height $123 \mathrm{~cm}$ (3-10th centile) and head circumference $52 \mathrm{~cm}$ (50-75th centile). She was receiving physical, speech and occupational therapy.

The short-term effects of insulin (maximum dose 12 IU/day) were not positive. The patient showed less motor activity and walked with an unstable gait. She appeared to be very introverted and not interested in her surroundings. She did not like to be touched and her behaviour was much more difficult to control. Therefore, treatment was stopped after 5 weeks. However, the patient showed improvement over the long term. Especially during the subsequent 3 months, the girl exhibited marked progress in gross and fine motor abilities (eg, she learned to swim) and in her cognitive abilities (eg, she could play with her dolls over a period of 20 minutes). She showed

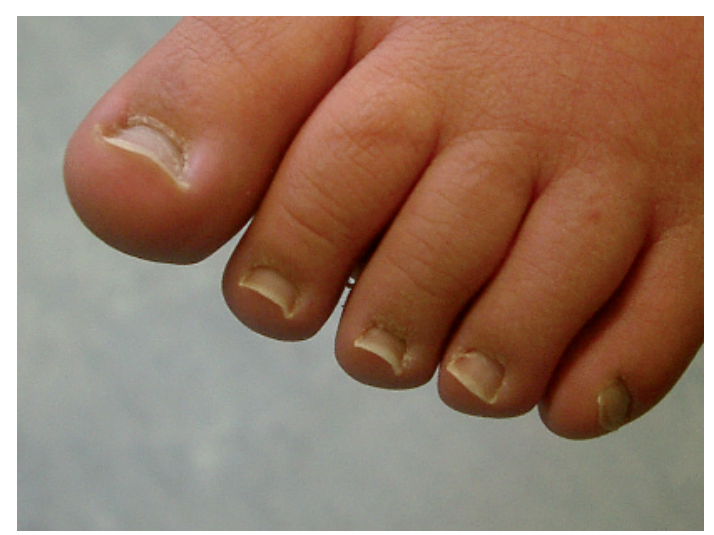

Figure 2 Patient 2. Dysplastic toenails. 
significant progress in verbal communication (eg, using more words and sentences; expressing wishes by using several words, eg, "May I go outside?") and social behaviour (eg, she was interested in other children and wanted to play with them). Education and behaviour control in everyday life were much easier.

\section{Patient 4}

This was a girl with karyotype 46, XX, del(22)(q13.32 mos), who was 6.5 years old at the time of diagnosis. At the age of 7 months, she was able to sit, and at the age of 15 months she was able to walk. She could also ride a bicycle and climb trees. At 6 years of age, she had a vocabulary of 40-50 words and could communicate in short sentences. She later became dyspractic and showed a marked loss of speech. At the age of 9 years, she exhibited autistic-like, self-aggressive behaviour, pain intolerance and restlessness. She could read and calculate with three-figure numbers. She had deep-set eyes, a rounded nose tip and a prominent chin.

At the start of treatment, aged 9.5 years, weight was $33 \mathrm{~kg}$ (75-90th centile) and height $130.8 \mathrm{~cm}$ (25-50th centile). She was on lamotrigin and receiving speech therapy and facilitated communication assistance.

The short-term effects (maximum dose $14 \mathrm{IU} /$ day) resulted in a more calm and balanced mood. The child showed better gross and fine motor abilities (increased motor activity with more precision in her movements, eg, in threading pearls), prolonged attention spans (eg, she typed up to two pages with assistance) and was more alert. She seemed to be more competent in situations of daily living and showed less selfaggressive behaviour, was more compliant towards educational interventions and took part in social activities. Positive longterm effects were seen, especially in motor skills, autonomy and activities of daily life (eg, slicing bread, using the remote control of the TV set, unloading the dishwasher). In general, the girl's attention span became longer and she showed a remarkable progress in her playing behaviour. She showed more interest in other children and strong positive emotional reactions to other people (eg, with longer periods of eye contact, showing happiness and sadness, comforting others). She began to imitate speech and to communicate with special devices. In everyday living she was more ready to compromise, could cope better with frustration and showed more flexibility. There were no reported side effects.

\section{Patient 5}

This boy had karyotype 46, XY, del (22)(q13.3). He was 20 months old at the time of diagnosis. He was sitting at 24 months and walking at 36 months. He grew too fast during the first 3 years of life. He had muscular hypotonia and developed hydronephrosis due to obstructive uropathy. His speech abilities at 10 months consisted of double syllables, but later stagnated. At the age of 5 years he showed autistic-like behaviour, restlessness, short attention spans, self-aggressive behaviour and no verbal communication. His phenotypic features were a rounded nose tip, puffy eyelids, persistent embryonal finger pads, and flat and hypoplastic fingernails.

At the start of treatment, he was aged 5.5 years with weight of $21.2 \mathrm{~kg}$ (90th centile) and height of $113.5 \mathrm{~cm}$ (75-90th centile). He was receiving physiotherapy.

Minor positive short-term effects of insulin (maximum dose $18 \mathrm{IU} /$ day), such as increased motor activity and better general attention were found. Positive long-term effects were seen in gross motor coordination abilities (eg, climbing stairs without assistance), or concentration (eg, being able to play longer). The boy showed more interest in his surroundings (eg, in listening to rhythms and songs). He reacted to speech and used nonverbal communication devices. He showed jealousy and joy to see his siblings again after being separated from them for some time (table 2). The only reported side effect was occasional nose bleeds.

\section{Patient 6}

This was a girl with karyotype: 46, XX, del (22)(q13.3).ish $\operatorname{del}(22)$ (q13.3)(ARSA-), who was 12 months old at the time of diagnosis. She had muscular hypotonia, was sitting at the age of 12 months, but could not walk without assistance at 2 years. Her growth range was between the 50 and 75 th centile, and she showed normal sweating. She had obstructive uropathy on the right side and mild aortal stenosis. At 26 months of age, she could walk only with assistance (holding on to someone's hand). She showed autistic-like behaviour with restlessness and no speech development. She did not use a pincer grip and did not notice when objects were removed. Her phenotypic features were a rounded nose tip, deep-set eyes and a squint, and flat and hypoplastic fingernails.

At the start of treatment, aged aged 26 months, she weighed $10.6 \mathrm{~kg}$ (3-10th centile), and her height was $89 \mathrm{~cm}$ (50-75th centile). She was receiving physiotherapy.

Short-term effects of insulin (maximum dose 8 IU/day) a liking to eat; she did not protest against being fed. She showed progress in gross and fine motor abilities (eg, she was able to point at pictures, she began to walk and could stand up without holding on). Her attention span was significantly increased. She showed more interest in her social surroundings, and began to imitate gestures and to use non-verbal communication devices. She gained much more emotional stability and flexibility. There were no reported side effects. Unfortunately, this was lost to follow-up so that potential long-term effects could not be noted.

\section{Summary of results}

The effects of insulin treatment are summarised in table 2 and averages are depicted in fig 3 . In all patients, the short-term and long-term effects seen and documented by the parents were comparable with the observations of the examiner and the clinical staff. Notably, all patients whose children showed improvements wanted to continue the treatment. No treatment effects on blood values including glucose, haemoglobin A1c, cortisol or insulin antibodies were found after 12 months of therapy. All auxological data remained normal.

\section{DISCUSSION}

In this exploratory clinical trial, six children suffering with $22 q 13$ deletion syndrome were given insulin intranasally for up to 1 year. Observations made by the children's parents, by the experimenter and by routine clinical staff not involved in the experiments (ie, observers blinded to insulin treatment) jointly indicate a beneficial effect of intranasal insulin on the cognitive and also motor development of the patients, suggesting that intranasal insulin might be a valuable tool to ameliorate the condition of patients with 22q13 deletion syndrome.

Owing to the small number of patients, their different chromosomal abnormalities (ring chromosome, mosaicism, large versus smaller deletions) and to the variability in age and physical/cognitive impairment, our results can only be taken as 


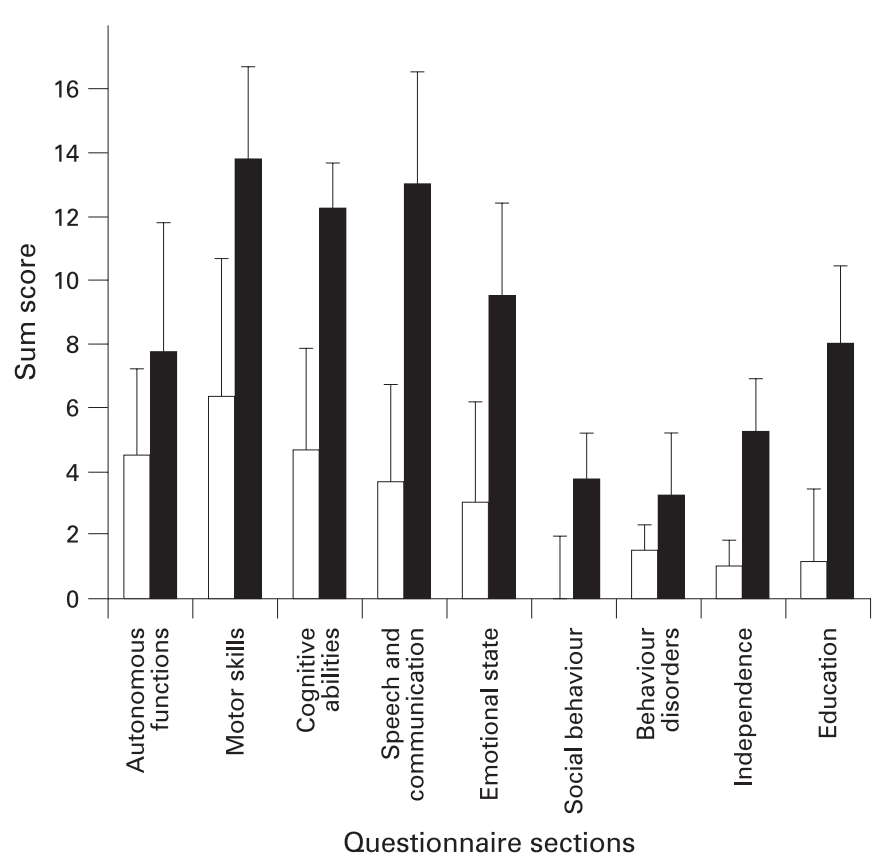

Figure 3 Effects of 6 weeks ( $n=6$; white bars) and 12 months $(n=4$; grey bars) of intranasal insulin administration as assessed by a questionnaire on developmental progress. ${ }^{13}$ Sum scores (mean (SEM)) are indicated for nine sections of questions with a range from -10 (most extreme degree of aggravation) to +10 (extremely positive development), with 0 indicating no changes.

a first indication of the beneficial effects of intranasal insulin in patients with 22q13 deletion syndrome.

The short-term effects of intranasal insulin were assessed in all six patients, but the long-term effects of continued insulin administration could only be assessed in four. In all six patients, the first positive changes occurred after 1 week of treatment (4-6 IU insulin/day), with particular improvement in restlessness and prolongation of attention span. After 6 weeks, significant progress could be seen in four of the six patients, primarily in control and coordination of gross and fine motor functions, attention span and control of behaviour in everyday life. These changes were corroborated by similar observations made by non-involved therapists. After 1 year of treatment, the four children under observation continued to show progress, primarily in motor functions (eg, strength, new acquired functions), understanding of speech, use of communication devices and prolonged attention spans, improved hand functioning and more autonomy in everyday life.

Patient 3 , the least impaired patient, was the only one who showed unexpected negative changes in mood, movement and tactile sensitiveness in the first weeks of treatment. These changes disappeared after the premature end of treatment and were followed by remarkable improvements during the subsequent 3 months. Because patients with 22q13 deletion syndrome often show regression of skills and subsequent regain, it is difficult to attribute this course of events to the insulin treatment, although it may have contributed to initially enhance and, thus, overstrained perception. Another patient (patient 5) only showed minor beneficial short-term effects and less pronounced long-term effects. Apart from occasional nose bleeding in one patient, no other side effects were reported, particularly hypoglycaemia due to intranasal insulin.

The mechanisms behind our observations cannot be derived from our data. The ProSAP2/Shank3 gene is preferentially expressed in cortex, cerebellum and hippocampus. It encodes a protein involved in the stability of the postsynaptic density (PSD) of excitatory neurons (a highly specialised submembraneous network of proteins). Therefore, haploinsufficiency of the ProSAP2/Shank3 gene as found in patients with 22q13 deletion syndrome might impair the development of dendritic spines and even cause degradation of synapses, resulting in the impairments that are seen in cognition and in gross and fine motor functions. ${ }^{5}$

Intranasal administration effectively delivers neuropeptides to the central nervous system (CNS), bypassing the blood-brain barrier and avoiding systemic side effects. Using this route of administration, a direct effect on central nervous signalling pathways is possible. ${ }^{615}{ }^{16}$ Intranasal administration of insulin has been shown to influence hippocampus-dependent declarative memory function in healthy volunteers, ${ }^{7-10}$ and improves cognition and mood in patients with AD. ${ }^{11}{ }^{12}$ Insulin may be expected to increase CNS glucose uptake, thereby improving neuronal function, which is particularly relevant in patients with cognitive impairments. ${ }^{17}$ Synergistically, insulin may enhance synaptic plasticity via glutamatergic/GABAergic receptors and phosphoinositol 3-kinase dependent mechanisms, although these processes probably develop with some delay. ${ }^{18}$ It has been shown that insulin receptor substrate protein 53 (IRSp53) an insulin receptor tyrosine kinase substrate, may improve the PSD by interacting with ProSAP/Shank and may contribute to the morphological reorganisation of spines and synapses after insulin receptor activation. ${ }^{19}$ Intranasal insulin may also stimulate this process in cases of reduced availability of ProSAP/Shank proteins by increasing the expression of the local dendritic scaffolding protein PSD 95, thus partially compensating for the reduced availability of ProSAP/Shank proteins and inducing cognitive improvements. Previously, intranasal insulin was shown to be more effective in patients with cognitive impairments who do not carry the apolipoprotein $\mathrm{E}$ (APOE) $\varepsilon 4$ allele, a genetic risk factor for $\mathrm{AD}^{20}$ In addition, women appear to benefit from the cognitive effects of intranasal insulin to a greater extent than men. ${ }^{9}$ The APOE- $\varepsilon 4$ status of our patients is not known and the small sample size prevents any conclusions on differential gender effects. It would likewise be of interest if the reaction to intranasal insulin is affected by deletion size, as this has been previously shown to correlate with some features of developmental retardation. ${ }^{21}$ Clearly, future studies will have to address the question of how these factors may influence insulin effects in children with developmental delay.

To our knowledge, this is the first report on intranasal insulin treatment in children, in particular in patients with 22q13 deletion syndrome. As the natural development in those children is unknown and the exploratory nature of our experiments prevented the inclusion of a placebo group, only tentative conclusions can be drawn from our results. Further and more systematic studies will be necessary to elucidate whether the beneficial effects found in our study can also be obtained in greater samples of patients, with a particular emphasis possible side effects of the compound. Enhanced dose regimens might even lead to more pronounced developmental improvements. The clinically astonishing short-term changes found in our study indicate an improving effect of intranasal insulin treatment, suggesting that insulin given in parallel with physical, speech and occupational therapy may support learning processes in patients with $22 \mathrm{q} 13$ deletion syndrome. 
Acknowledgements: We are grateful to the father of patient 1, who made these clinical trials possible by intensive literature research, in a tireless effort to improve his son's quality of life. Aero Pump GmbH (Hochheim/Germany) generously provided us with precision nasal air pump. We thank B Berner for linguistic advice.

Competing interests: None.

Patient consent: Obtained.

\section{REFERENCES}

1. Watt JL, Olson IA, Johnston AW, Ross HS, Couzin DA, Stephen GS. A familial pericentric inversion of chromosome 22 with a recombinant subject illustrating a 'pure' partial monosomy syndrome. J Med Genet 1985;22:283-87.

2. Nesslinger NJ, Gorski JL, Kurczynski TW, Shapira SK, Siegel-Bartelt J, Dumanski JP, Cullen RF Jr, French BN, McDermid HE. Clinical, cytogenetic, or molecular characterization of seven patients with deletions of chromosome 22q13.3. Am J Hum Genet 1994;54:464-72.

3. Phelan MC, Rogers RC, Saul RA, Stapleton GA, Sweet K, McDermid H, Shaw SR, Claytor J, Willis J, Kelly DP. 22q13 deletion syndrome. Am J Med Genet 2001;101:91-99.

4. Havens JM, Visootsak J, Phelan MC, Graham JM, Jr. 22q13 deletion syndrome: an update and review for the primary pediatrician. Clin Pediatr (Phila) 2004;43:43-53.

5. Boeckers TM, Bockmann J, Kreutz MR, Gundelfinger ED. ProSAP/Shank proteins - a family of higher order organizing molecules of the postsynaptic density with an emerging role in human neurologicalal disease. J Neurochem 2002;81:903-10.

6. Born J, Lange T, Kern W, McGregor GP, Bickel U, Fehm HL. Sniffing neuropeptides: a transnasal approach to the human brain. Nat Neurosci 2002;5:514-16.

7. Benedict C, Hallschmid M, Hatke A, Schultes B, Fehm HL, Born J, Kern W. Intranasal insulin improves memory in humans. Psychoneuroendocrinology 2004;29:1326-34.

8. Benedict C, Hallschmid M, Schmitz K, Schultes B, Ratter F, Fehm HL, Born J, Kern W. Intranasal insulin improves memory in humans: superiority of insulin aspart. Neuropsychopharmacology 2007;32:239-43

9. Benedict C, Kern W, Schultes B, Born J, Hallschmid M. Differential sensitivity of men and women to anorexigenic and memory-improving effects of intranasal insulin. J Clin Endocrinol Metab 2008;93:1339-44.
10. Hallschmid M, Benedict C, Schultes B, Born J, Kern W. Obese men respond to cognitive but not to catabolic brain insulin signaling. Int J Obes (Lond) 2008;32:275-82.

11. Reger MA, Watson GS, Green PS, Baker LD, Cholerton B, Fishel MA, Plymate SR, Cherrier MM, Schellenberg GD, Frey WH, Craft S. Intranasal insulin administration dose-dependently modulates verbal memory and plasma amyloid-beta in memoryimpaired older adults. J Alzheimers Dis 2008;13:323-31.

12. Reger MA, Watson GS, Green PS, Wilkinson CW, Baker LD, Cholerton B, Fishel MA, Plymate SR, Breitner JC, DeGroodt W, Mehta P, Craft S. Intranasal insulin improves cognition and modulates beta-amyloid in early AD. Neurology 2008;70:440-8.

13. Kiernan C, Reid B. Pre-verbal communication schedule (PVCS) short version (1987) In: Sarimski K, Steinhausen HC, eds. Geistige Behinderung und schwere Entwicklungsstörung. Kinder-Diagnostik-System 2. Hogrefe: Göttingen, 2007:81-83.

14. Sarimski K, Steinhausen HC. KIDS Kinder Diagnostik System 2. Geistige Behinderung und schwere Entwicklungsstörung. Hogrefe: Göttingen, 2007.

15. Thorne RG, Frey WH. Delivery of neurotrophic factors to the central nervous system: pharmacokinetic considerations. Clin Pharmacokinet 2001;40:907-46.

16. Thorne RG, Pronk GJ, Padmanabhan V, Frey WH. Delivery of insulin-like growth factor-I to the rat brain and spinal cord along olfactory and trigeminal pathways following intranasal administration. Neuroscience 2004;127:481-96.

17. de la Monte SM, Wands JR. Review of insulin and insulin-like growth factor expression, signaling, or malfunction in the central nervous system: relevance to Alzheimer disease. J Alzheimers Dis 2005;7:45-61.

18. Lee CC, Huang CC, Wu MY, Hsu KS. Insulin stimulates postsynaptic density-95 protein translation via the phosphoinositide 3-kinase-Akt-mammalian target of rapamycin signaling pathway. J Biol Chem 2005;280:18543-50.

19. Bockmann J, Kreutz MR, Gundelfinger ED, Bockers TM. ProSAP/Shank postsynaptic density proteins interact with insulin receptor tyrosine kinase substrate IRSp53. J Neurochem 2002;83:1013-17.

20. Reger MA, Watson GS, Frey WH, Baker LD, Cholerton B, Keeling ML, Belongia DA, Fishel MA, Plymate SR, Schellenberg GD, Cherrier MM, Craft S. Effects of intranasal insulin on cognition in memory-impaired older adults: modulation by APOE genotype. Neurobiol Aging 2006;27:451-58.

21. Wilson HL, Wong AC, Shaw SR, Tse WY, Stapleton GA, Phelan MC, Hu S, Marshall $\mathrm{J}$, McDermid HE. Molecular characterisation of the 22q13 deletion syndrome supports the role of haploinsufficiency of SHANK3/PROSAP2 in the major neurologicalal symptoms. J Med Genet 2003;40:575-84.

\section{BMJ Careers online re-launches}

BMJ Careers online has re-launched to give you an even better online experience. You'll still find our online services such as jobs, courses and careers advice, but now they're even easier to navigate and quicker to find.

New features include:

- Job alerts - you tell us how often you want to hear from us with either daily or weekly alerts

- Refined keyword searching making it easier to find exactly what you want

- Contextual display - when you search for articles or courses we'll automatically display job adverts relevant to your search

- Recruiter logos linked directly to their organisation homepage - find out more about the company before you apply

- RSS feeds now even easier to set up

Visit careers.bmj.com to find out more. 


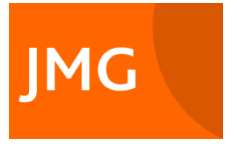

\section{Intranasal insulin to improve developmental delay in children with 22q13 deletion syndrome: an exploratory clinical trial}

H Schmidt, W Kern, R Giese, et al.

J Med Genet 2009 46: 217-222 originally published online October 23, 2008

doi: 10.1136/jmg.2008.062141

Updated information and services can be found at:

http://jmg.bmj.com/content/46/4/217.full.html

\begin{tabular}{|c|c|}
\hline & These include: \\
\hline References & $\begin{array}{l}\text { This article cites } 19 \text { articles, } 6 \text { of which can be accessed free at: } \\
\text { http://jmg.bmj.com/content/46/4/217.full.htm/\#ref-list-1 }\end{array}$ \\
\hline & $\begin{array}{l}\text { Article cited in: } \\
\text { http://jmg.bmj.com/content/46/4/217.full.html\#related-urls }\end{array}$ \\
\hline $\begin{array}{l}\text { Email alerting } \\
\text { service }\end{array}$ & $\begin{array}{l}\text { Receive free email alerts when new articles cite this article. Sign up in } \\
\text { the box at the top right corner of the online article. }\end{array}$ \\
\hline $\begin{array}{r}\text { Topic } \\
\text { Collections }\end{array}$ & $\begin{array}{l}\text { Articles on similar topics can be found in the following collections } \\
\text { Dementia ( } 33 \text { articles) } \\
\text { Memory disorders (psychiatry) (56 articles) }\end{array}$ \\
\hline
\end{tabular}

Notes

To request permissions go to:

http://group.bmj.com/group/rights-licensing/permissions

To order reprints go to:

http://journals.bmj.com/cgi/reprintform

To subscribe to BMJ go to:

http://group.bmj.com/subscribe/ 